\title{
Getting Real about Adapting to Climate Change: Using 'Real Options' to Address the Uncertainties
}

\author{
Leo Dobes ${ }^{1}$
}

\begin{abstract}
Scientists predict that some climate change is already inevitable, even if greenhouse emissions are stabilised. Adaptation strategies will be of comparable importance to reducing emissions. However, the specific effects of climate change are currently unknowable, especially at the local level. Given this uncertainty, deterministic adaptation strategies are inappropriate. Rather than building 'worst-case scenario' sea walls, for example, strong foundations can be laid - so that walls can be built (or not built) in future to match actual climatic conditions without incurring unnecessary upfront expense. Other examples of such 'real options' are provided to illustrate the feasibility of the approach.
\end{abstract}

\section{Introduction}

Scientists have for some time predicted that climate change is already inevitable, even if greenhouse emissions are stabilised (for example, Houghton et al. 1990: xxii). Pittock (2003: 46) points out that inertia and time lags in the climate system will result in climate-change impacts on Australia continuing 'long after greenhouse gas emissions have been reduced, and will be dictated largely by cumulative emissions in the past century and the coming decades'.

If we accept that increased atmospheric concentrations of greenhouse gases cause climate change, then logic dictates that we should already be thinking as much about adapting to climate change as about mitigating (reducing) emissions. ${ }^{2}$ But adaptation strategies require an entirely different policy approach from mitigation measures.

\footnotetext{
${ }^{1}$ Crawford School, the Australian National University, Leo.Dobes@dobes.com.au

2 The author is grateful to the Editor and each of the three anonymous referees for commenting on an early draft of this paper. One referee proposed that the paper explicitly acknowledge that 'climate change has already been detected and has been rigorously attributed to human causes. ... The hotter, drier climate is already here ...'. The present author, however, respectfully disagrees with this contention. While a significant (but not unanimous) body of scientific opinion supports the view that anthropogenic emissions of greenhouse gases are causing climate change, the potential contribution of non-anthropogenic causes has yet to be established. In any case, the argument in this paper does not depend on the existence of any current change in climate, but only on the possibility of future climate change (for whatever reason), and uncertainty about its extent. Nor does it depend on the attribution of climate change to anthropogenic factors.
} 
By and large, policymakers can select a mitigation measure such as a carbon tax, or the replacement of incandescent globes with fluorescent lighting, and estimate with a degree of certainty the expected reduction in emissions. Within reasonable bounds, the social costs of each measure can also be estimated with some certainty. Policymakers can therefore be relatively confident about choosing the most cost-effective measure or mix of measures for reducing national levels of greenhouse emissions.

Adaptation strategies, in contrast, involve a great deal of uncertainty. Climate-change models are based on global scenarios whose likelihood of occurrence is difficult to determine in practice. And while models are improving, predicting climatic effects at the local level - where adaptation necessarily needs to take place - entails additional uncertainty. Although Australians have considerable experience in adapting to climatic extremes, there is little specific information available to guide decision-makers facing new circumstances.

In acknowledging - rather than ignoring - the existence of uncertainty about the specific extent and effects of future climate change, this article posits that past thinking has been overly linear and deterministic. At the risk of generalisation, the focus has been on identifying a likely effect (for example, melting of the Arctic ice cap), the consequential risk (for example, rising sea levels), and the 'obvious' remedy (for example, building sea walls). Thinking at the political level in Australia has similarly focused on identifying potential risks and responses, and has advanced little for almost two decades.

But deterministic approaches are a potentially misleading basis for implementing adaptation measures because the specific extent and timing of any future climatic change is highly uncertain. Except by pure chance, deterministic responses are likely to be either inadequate (flooding due to sea walls being too low, or built too late) or unnecessarily wasteful of scarce community resources (sea walls too high, or built earlier than needed).

The paper first reviews briefly some of the literature on adaptation, concluding that knowledge of the effects of climate change - especially at the local level - is subject to a high degree of uncertainty and is often presented as little more than very general lists of various risks. A review of the conceptual thinking by Australian governments about adaptation issues is shown in the next section to have changed little over the last two decades, and two examples are provided to illustrate the tension between the bureaucratic preference for deterministic planning and the uncertainties that surround climate change. The main part of the paper presents a series of examples illustrating how the problem of uncertainty can be more appropriately addressed by increasing the flexibility of adaptation measures by employing 'real options'. The final part of the paper proposes that the role of government in adaptation to climate change should be limited to issues that involve genuine market failure. 


\section{Impacts assessment: the Mikado's little list ${ }^{\mathbf{3}}$}

Although adaptation as an issue has not been entirely ignored in the past, the scientific and academic literature appears to have blossomed only in the last two or three years.

Contributors to the latest Intergovernmental Panel on Climate Change report are aware of the body's comparative neglect of adaptation issues over the last decade and a half. Klein et al. (2007: 753), for example, acknowledge that the UNFCCC [United Nations Framework Convention on Climate Change], its subsidiary bodies and Member Parties have largely focused on mitigation', and Schneider et al. (2007: 797) concede that 'the scientific literature on [adaptation] is less well developed than for mitigation, and the conclusions are more speculative in many cases'.

At one extreme, it is possible that some in the scientific and environmentalist communities may have subscribed, consciously or unconsciously, to a paradigm of salvation in which only mitigation strategies can save the world from climatic catastrophe. In Tol's (2005: 572) view, 'it was politically incorrect to speak about adaptation to climate change, because it presumably implies accepting defeat in the battle against evil emissions'. While Pielke et al. (2007: 597) agree, they also point out that 'during early policy discussions on climate change in the 1980s, adaptation was understood to be an important option for society'.

A more liberal explanation of the comparative neglect of adaptation may be that the lack of scientific certainty about climate change made analysts cautious until the IPCC's Third Assessment Report in 2001. In a 1995 IPCC synthesis report, Bolin et al. (1995: para 2.5), for example, state that 'there are inadequate data to determine whether consistent global changes in climate variability or weather extremes have occurred over the $20^{\text {th }}$ century'. Only with the drama of more recent extreme weather events such as protracted drought in Australia, Hurricane Katrina in the United States, severe floods in many parts of the world, the 2003 heat waves in Europe, as well as the publicity surrounding the 2006 Stern Review, has public attention focused on the possible effects of climate change.

A good deal of the emphasis in the scientific literature has been the identification of generic risks and vulnerabilities. The impacts of climate change are often assessed in the technical literature in terms of criteria (Schneider et al. 2007: 785) such as the magnitude of an effect (for example, the number of people or the area affected) or its timing (soon, or in the distant future), or persistence and reversibility (for example, the loss of major ice sheets or the shutdown of

3 The allusion is to eponymous productions of the Gilbert and Sullivan operetta where the Mikado produces a 'little list' of people who irritate him. The list is, in fact, quite lengthy, follows no underlying principle, and varies from production to production to ensure 'relevance'. 
the meridional overturning circulation). Further, 'the literature on adaptation costs and benefits remains quite limited and fragmented in terms of sectoral and regional coverage. ... Much of the literature ... is focused on sea-level rise ... and agriculture' (Adger et al. 2007: 724-5).

A medley of lists and categories of various 'vulnerabilities' has developed to indicate areas of greatest priority in addressing adaptation to climate change. For example, Schneider et al. (2007: 787-9) list categories that include often-overlapping areas such as food supply, aggregate market impacts and distribution, health, water resources, infrastructure, fire, marine ecosystems and biodiversity, and so on. But such lists in themselves provide little or no guidance on what should be done, or when, or by how much, by way of adaptation.

The academic, policy-related literature ranges across perspectives as diverse as Orlove's (2005) anthropological examination of the collapse of the classic Mayan civilisation and the abandonment of Viking settlements in Greenland, England's (2007) exploration of legal liability aspects, Berkhout's (2006) pessimism about the willingness of commercial organisations to experiment in adaptation techniques, warnings by McMichael (2004) and Woodruff et al. (2006) about the spread of malaria and dengue fever, reports about the melting of roadways and buckling of railway lines by DuVair et al. (2002), and the spectre of an invasion of Australia's shores by environmental refugees from the Pacific Basin raised by Furnass (2007), based on work by Dupont and Pearman (2006). Again, however, there is no clear indication of what exactly should be done, or when, or by how much.

Both the scientific and the policy-oriented literature suffer from the problem of being based on the output of climate-change models. They are therefore able to provide little more than general indications of potential climate risks because the results from climate-change models are average (that is, trend) values, whereas adaptation necessarily needs to address extreme weather events (the outlying probabilistic points around the trend line). More importantly, climate models are based on simulations of possible scenarios of future atmospheric concentrations of greenhouse gases. And there is enormous uncertainty about which scenario is the most likely, or even whether governments will reach and enforce a clear international agreement on mitigation levels that might help determine a likely scenario.

The upshot of this situation, unfortunately, is that the information currently available to governments and the public offers very little certainty about the specific effects of any climate change, and hence cannot provide useful guidance regarding the extent or timing of policy responses. 


\section{Australian governments: more of the same}

Australia's political consideration of adaptation issues has, to date, also focused mainly on cataloguing risks and promoting further research, with little tangible development over almost two decades of practical policy frameworks for implementing adaptation responses.

On 11 October 1990, the Minister for Arts, Sport, the Environment, Tourism and Territories, Ros Kelly, and the Minister for Primary Industries and Energy, John Kerin, jointly announced that the Commonwealth Government had adopted an interim planning target to reduce emissions of greenhouse gases by 20 per cent by the year 2005. The two ministers also announced that a referral had been made to the Industry Commission to prepare a report on the cost-benefit implications for Australian industry of such a target, and that Ecologically Sustainable Development working groups would be established to report to the Government on a range of greenhouse-gas-related measures. However, there was no reference to adaptation issues in the announcement itself.

The Industry Commission (1991:2) report commented that the state of scientific knowledge at the time did 'not allow any reasonable estimate to be made of the impacts that would be avoided by a global reduction in greenhouse gas emissions' but refers only in passing to the possibility of adaptation measures. The Ecologically Sustainable Development working groups issued various sectoral reports in 1991 but do not appear to have covered directly issues related to adaptation to climate change. Nor does the National Strategy for Ecologically Sustainable Development (Commonwealth of Australia 1992b) - an outcome of the working group process - deal with adaptation.

The first Special Premiers' Conference, held in October 1990, issued a communiqué announcing an intention to develop an Intergovernmental Agreement on the Environment (IGAE), and Prime Minister Paul Keating's One Nation statement of 26 February 1992 announced that agreement had been reached on this. Schedule 5 of the IGAE provided for the development of a National Greenhouse Response Strategy (Commonwealth of Australia, 1992a), which was published in December 1992 with the endorsement of the Council of Australian Governments (COAG).

Adaptation does feature, however, in both of the main parts of the National Greenhouse Response Strategy (NGRS): 'Specific Sectoral Strategies' and 'Measures Already Underway'. Its objective is stated as being to 'protect Australia's natural, human and built environment from the potential impacts of the enhanced greenhouse effect' (Commonwealth of Australia 1992a). Strategies for achieving this aim include:

- conducting research into the potential impacts of the enhanced greenhouse effect, including development of techniques to assess vulnerability; 
- assessment of the vulnerability of the natural, built and human environment to climate change;

- incorporation of planning for possible impacts of the enhanced greenhouse effect into existing conservation and planning strategies;

- incorporation of information on the potential impacts of the enhanced greenhouse effect into disaster planning; and

- ensuring that natural-resource management (for example, agriculture and forestry) regimes take into account the potential impacts of climate change.

Some of the measures identified as being already under way (Commonwealth of Australia 1992a: 60-1) included research by the CSIRO, various monitoring activities to assess the extent and impact of climate change, expert workshops, and the development by 'some State and Territory Governments and local councils [of] ... new planning regimes in recognition of the potential for changes in sea level, flooding and storm surges'.

Apart from a reformulation of the NGRS into the 1998 National Greenhouse Strategy (NGS) following a review initiated in 1996 (Productivity Commission 1999: 227), COAG appears to have given little or no active attention to the issue of adaptation for more than a decade after it endorsed the NGRS. It was only in February 2006 that COAG agreed to a Climate Change Plan of Action (http://www.coag.gov.au/meetings/100206/index.htm) that included development of a national adaptation framework, and the April 2007 meeting of COAG endorsed a National Climate Change Adaptation Framework.

The new National Climate Change Adaptation Framework reveals little conceptual progress from the content of the 1992 NGRS. It proposes the establishment of an Australian Centre for Climate Change Adaptation (since established at Griffith University) and identifies additional risks such as fires, mosquito-borne infections, heatwaves, and the spread of invasive species. Overall, however, it is at least arguable that it does little more in essence than the NGRS in calling for more research, identification and assessment of risks and vulnerabilities, and their incorporation into decision-making in sectoral areas of concern.

State governments have separately issued various reports and action plans. The Victorian Government has published a comprehensive climate-change adaptation program that includes risk assessments and publications such as State of Victoria (2007). Other states have similar plans and publications, and non-governmental organisations such as the Agriculture and Land Management Working Group (2003) and Engineers Australia (2004) have also addressed issues of risk and adaptation. However, the review of likely health impacts of climate change by the Department of Health of Western Australia (2007) is unusual in that the Executive Summary recognises explicitly that the lack of detailed 
knowledge of future climatic conditions in Western Australia ... did not allow for a comprehensive and quantitative assessment of health impacts'.

\section{Uncertainty makes deterministic planning dangerous}

As well-intentioned as it might be, deterministic planning in the face of inevitable uncertainty about the detail of climate change poses the risk of serious misallocation of society's resources. An example of the tension between the lack of knowledge about specific climate-change effects, and the bureaucratic impulse to plan, appears in Voice et al. (2006). It is worth quoting at length:

There have been many evaluations of severe wind risk in the current climate ... There has been less work performed on wind risk in a warmer world ... Little progress has been made since [a cited 2001 study] on improving the climate change scenarios that dictate the precise amount of future vulnerability. (Section 6.3.1: 50)

While specific case studies of the vulnerability of ports to climate change have not been performed, ports have generally used the National Committee on Coastal and Engineering guidelines ... to make allowance for climate change effects. ... Major new port infrastructure is thoroughly assessed for the impacts of climate change in the design phase. ... For example, the proposed new offshore wharf structure and expanded coal terminal in the Port of Abbot Point in Queensland ... studied a number of greenhouse potential impacts. The new facilities were designed for expected water level changes predicted over the next 100 years (conservatively estimated at 0.2 metres to 0.5 metres) ... New port infrastructure therefore is well prepared for the impact of climate change. (Section 6.3.2: 50-1)

The following piece of advice by the federal Department of Climate Change on how to adapt to climate change also illustrates the point well: 'Early planning for the impacts of climate change is likely to bring considerable advantages. Many decisions made today will have consequences for decades. It is cheaper, for example, to design new housing or infrastructure to cope with a future climate than to retrofit later.' (http://www.greenhouse.gov.au/impacts/howtoadapt/ indexs.html; viewed 6 July 2008, emphasis added)

One presumes that the Department undertook some careful calculations before proffering this advice. But what do such sums amount to in the face of uncertainty about the extent and timing of specific climate-change effects for each locality in Australia? Is it really cheaper to build a house designed to withstand an absolute worst-case scenario (and which one?), or did the Department mean something less drastic? Indeed, it might in fact be even cheaper to build a flimsy non-climate-proofed house now, and rebuild it, if necessary, once the true extent and timing of any climate change becomes much more 
certain. And would it not be socially more desirable to keep current expenditure on housing to a minimum, in case cities need to be redesigned to take account of mitigation measures that reduce transport needs and increase housing density?

Clearly, uncertainty about the specific nature and extent of any future climate change militates against apparently straightforward, deterministic policy prescriptions.

\section{'Real options': a cleverer option}

A more fruitful perspective on measures for adapting to climate change is that they resemble investment decisions under conditions of uncertainty.

An investor facing the possibility of a high return on an asset can purchase an option, rather than the more expensive share itself. This (financial) option gives the investor the contractual right, but no obligation, to purchase the asset should its value rise above a specified level ('the strike price'), on or before a specified date. If the market price of the asset rises above the specified 'strike price', the investor can profit by exercising the option and so obtain the share at below market price. If the share price remains low, or falls, the investor forgoes the opportunity to purchase the asset because there would be no gain in doing so, but loses only the cost of the option that was purchased. Such options are valuable because they allow an investor to delay a final decision on purchasing a relatively more expensive share until there is greater certainty about the share price.

An analogous possibility often exists in the realm of physical (so-called real) capital. An everyday example of a 'real option' might be a couple buying a house, but uncertain about when, or if, they will have children, or how many children. Buying a large house immediately could be unnecessarily costly if they remain childless, or if they delay starting a family for a significant time. But they could buy a smaller, cheaper house on a suitable block of land and extend it later, as required. The smaller house in effect 'embeds' an option to extend, but there is no obligation to do so if the family remains small. The couple can delay a final decision on the size (and hence the full cost) of the house until better information becomes available regarding specific family size.

In applying the 'real options' approach to decisions made by firms, management theorists often use the term 'strategic options' to reflect deliberate commercial strategies to create flexibility in investment decisions where outcomes are uncertain. Raynor (2007), for example, employs this perspective in analysing joint ventures and the entry of firms into foreign markets. Nerkar et al. (2007) apply similar reasoning to the acquisition of patents.

Dixit and Pindyck (1994) explore in detail the methodology for evaluating real options, and the use of such values in cost-benefit and investment analysis. 
They point out (pp.3-4) that most investment decisions share, in varying degrees, the following key characteristics:

- The investment is partially or completely irreversible. That is, at least part of the initial cost is 'sunk' because it cannot be recovered even if the rest of the investment process does not proceed. If all costs were recoverable, there would be no value in delaying the full implementation of the investment.

- There is uncertainty over the future rewards or payoffs from the investment.

- There exists the ability or opportunity to delay the timing of the investment, at least partially.

- More information about potential rewards or payoffs (but never complete certainty) becomes available during any procrastination.

Apart from its greater realism, the real options approach represents an important analytical advance on orthodox Net Present Value analyses that take as given assumed future streams of costs and revenues or benefits. The concept is also readily applicable to the design and evaluation of measures intended to ameliorate the effects of any future climate change.

\section{Identifying and creating 'real options' in adapting to climate change}

The potential application of the real options approach to climate-change adaptation measures can be illustrated with a number of hypothetical but realistic examples.

One example is in the construction of a new airport runway. In a hotter climate, longer runways may be required to allow planes to develop sufficient lift to take off safely with full loads. (An alternative may be more-powerful engines, but noise issues may preclude this option.) It would be expensive to build a long runway immediately, and may turn out to be an unnecessary cost if temperatures do not increase as much as initially anticipated. In this situation of uncertainty about climate-change impacts, a 'real option' could be the construction of a normal runway, but accompanied by the purchase of additional land at the end of the runway to allow for a possible extension later, if required. In other words, the airport operator does not need to commit the full extent of funding immediately.

Because the additional land can also be leased to short-term users for such things as freight warehouses, car parking, grazing of animals, and so on, the cost of the 'land purchase' option can be offset to some extent. But an even more effective approach could be to build a normal runway and purchase only an option to buy the additional land at the end of the runway. That is, enter into a contract with the owner of the land to purchase it within a specified period, for a specified sum, if some specified temperature criterion is met. An option to purchase the land would normally be cheaper than buying it outright. 
A similar heuristic could be used to address the problem of flooding in low-lying areas. As an alternative to blocking development in such areas, or building high protective barriers immediately, it may be worthwhile constructing only the base of a wall or embankment, but one that is capable of supporting a, say, 10-metre wall. This approach creates an option to build a high wall later, if required. It also affords the option of building a low wall, and raising it later, if required, or just providing a solid base for sandbagging for occasional emergencies. In other words, the full cost of a high wall is not incurred unless, and until, it is really required, and the base can be used to ameliorate the effects of less extreme weather events as well.

Military equipment often embeds real options. For example, ships may be 'fitted for but not with' missile-launching or other capabilities. This approach reduces the initial capital expenditure and affords the military the option of acquiring the most up-to-date equipment at the time that it is actually needed. If it is not needed, little additional opportunity cost is incurred. A similar approach could be applied to transport vehicles. Trains or buses can be 'fitted for but not with' larger air-conditioning units, for example, but the equipment would be installed in the future only if increased temperatures warranted the additional expenditure.

Long-lived infrastructure such as a road or railway is particularly suited to the real-options investment approach. For example, there may be considerable uncertainty about the extent to which low-lying land will be more flood-prone in, say, 2050, but a road or railway needs to be built immediately in the area. Rather than constructing roads or railways on expensive raised embankments, or choosing longer alternative routes, one approach may be to purchase additional adjoining land to form a wider corridor. If required in future, the corridor can be used to build levee banks or to place gabions to protect the road or railway from floodwaters. Sunk costs can be minimised if the land is not in fact required in the future, by selling it to housing developers, or leasing it to owners of pipelines, or telecommunications or electricity lines.

Nor do cities or buildings necessarily require the immediate development and use of expensive new materials and designs. Rather than investing immediately in expensive new technology, cheaper options that can buy time include making provision for the future use of shade blinds for windows and walls, increasing the albedo ${ }^{4}$ of walls and roofs through painting, or the planting of deciduous vegetation next to or near buildings and along streets. Taha et al. (1997), for example, found that a moderate increase in vegetation could reduce temperatures in California's South Coast Air Basin by $2-3^{\circ} \mathrm{C}$, with comparable results in other studies such as Shashua-Bar and Hoffman (2004). Street trees in

\footnotetext{
4 In general terms, albedo is the 'reflectivity' of an object. Black bodies have zero or low albedo, and bright matter such as ice or snow have a high albedo.
} 
particular can reduce the sunk social cost of investment through the positive externality of enhancing the attractiveness of urban areas.

In a rare application of the real-options approach, Nordvik and Liso (2004) model possible responses by building owners to climate change, finding that uncertainty about climate change may reduce rates of conversion (for example, to withstand higher winds) as well as reducing the scrapping of buildings, as well as maintenance effort: that is, the model posits increased economic lifetimes of buildings in the face of uncertainty. Another option may be to build cheaper houses and commercial accommodation with shorter design lives, and to reduce maintenance on them. This approach opens up the possibility of the earlier scrapping of buildings and reconstructing with materials that are more appropriate to whatever climatic conditions prevail at the time. Earlier scrapping of buildings will increase flexibility and options for redesigning whole cities for example to increase density — should that be found desirable in the future.

Application of the real-options approach is not limited to physical infrastructure. Australian farmers have practised the concept for many years in dealing with a historically highly variable climate. At times of insufficient water availability, farmers who have prepared their land for a cotton crop, for example, may exercise the option of planting sorghum instead. Other potential agricultural options include the operation of several farms in geographically diverse locations, rather than a single farm, and the use of versatile livestock such as the South African Meat Merino (see ABC (2006); and The Prime SAMM Society of Australia) which offers the option of producing either wool or meat, depending on weather and market conditions. The legendary cattle king, Sir Sidney Kidman, effectively created a real option with respect to cattle by acquiring a string of contiguous landholdings north to south across Australia to facilitate movement of his livestock from drought-affected areas to water and pasture elsewhere.

With appropriate input from medical practitioners, real options could also be developed for the health sector. In the case of concerns about the spread of malaria, research itself provides an option, and is preferable to expensive (and possibly misguided) investment in specialised malaria hospitals or training more medical personnel. An example of a real option might be for Australia to fund a specialist domestic or foreign company to undertake research into new anti-malarial drugs in return for cheap drugs to Australian residents in the event that malaria does become endemic.

Care also needs to be taken to incorporate real options into some popular mitigation strategies. An example is government subsidies for solar panels to reduce the use of fossil fuels. Such subsidies may come to be seen as incongruous in the future if predictions of more severe weather events such as the hailstorms in Sydney and Queensland become commonplace, and solar panels suffer extensive weather damage. To ensure continuity of electricity supply, a real 
option might be to include fittings on the panels during installation to allow later attachment of wire mesh or some other cheap protective device, in case hailstorms do become prevalent in the future.

With sufficient foresight, determination and creativity, it is possible to identify 'real options' for other areas of social and economic life that may be affected by future climate change. The identification of flexible options, not the deterministic prescription of 'obvious' solutions, should be the preferred approach to formulating adaptation policy.

\section{Steering, not rowing: the role of government}

It is not the intention here to explore in detail the appropriate role of governments in formulating adaptation strategies. But a case can readily be made for refocusing bureaucratic thinking and activity into the following areas:

- Addressing genuine instances of market failure, such as lack of information, by supporting research into likely effects of climate change, but at a specific level relevant to local conditions.

- Taking a leading role where externalities occur. For example, if levee banks are required to prevent flood damage, it will be necessary to ensure that the affected riparian landowners all build and maintain adequate flood defences to avoid flooding from neighbouring properties with inadequate levee banks. However, cost recovery - perhaps in the form of income-contingent loans proposed by Chapman (2006) - may be appropriate if land values are enhanced through government support.

- Identification and removal of bureaucratic impediments to adaptation by the private sector. (Local council bans on rainwater tanks in urban households are still well within living memory.)

- Fostering the identification of potential real options in adaptation strategies, and public dissemination of information on the results.

\section{Conclusion}

Although the 'real options' approach outlined above is addressed by established economic theory, it reflects the common sense that most humans apply to situations where there is uncertainty about the future. By not fully committing to a policy or course of action until more information becomes available, better outcomes are ultimately more likely. In economic terms, society as a whole can improve its wellbeing because it can attain its objectives using fewer resources, and those resources can be used for other purposes.

It may not always be easy to identify appropriate 'real options' for measures designed to adapt to climate change. But unless a serious effort is made to do so, governments will be tempted to spend too much, too soon. 


\section{References}

ABC 2006, 'Wool growers turn into meat producers', Landline program 8 October 2006, Australian Broadcasting Corporation, $<$ http://abc.net.au/landline/content/2006/s1757239.htm >.

Adger, W. N., Agrawala, S., Mirza, M. M. Q., Conde, C., O'Brien, K., Puhlin J., Pulwarty, R., Smit, B. and Takahashi, K. 2007, 'Assessment of adaptation practices, options, constraints and capacity', in Intergovernmental Panel on Climate Change: 717-43.

Agriculture and Land Management Working Group 2003, Implications of Climate Change and Greenhouse policy for Rural and Regional Australia, report to the Commonwealth Government as part of the Government-Business Climate Change Dialogue, Canberra.

Chapman, B. 2006, Government Managing Risk. Income Contingent Loans for Social and Economic Progress, Routledge, U.K.

Commonwealth of Australia 1992a, National Greenhouse Response Strategy, December, Australian Government Publishing Service, Canberra.

Commonwealth of Australia 1992b, National Strategy for Ecologically Sustainable Development, December, Australian Government Publishing Service, Canberra.

Council of Australian Governments (various years 1992-2007), COAG Meeting Outcomes, http://www.coag.gov.au/meetings/100206/index.htm, viewed 27 February 2008.

Department of Health of Western Australia 2007, Health Impacts of Climate Change: Adaptation Strategies for Western Australia, Perth.

Dixit, A. K. and Pindyck, R. S. 1994, Investment Under Uncertainty, Princeton University Press, New Jersey.

Dupont, A. and Pearman, G. 2006, 'Heating up the Planet. Climate Change and Security', Paper 12, Lowy Institute, Sydney.

duVair, P., Wickizer, D. and Burer, M. J. 2002, 'Climate change and the potential implications for California's transportation system', in The Potential Impacts of Climate Change on Transportation: Workshop Summary and Proceedings, U.S. DOT (Center for Climate Change and Environmental Forecasting) in cooperation with U.S. EPA, U.S DEA, U.S. GCRP, at $<$ http://climate.dot.gov/publications/workshop1002/duvair.pdf $>$, viewed 19 March 2008.

Engineers Australia 2004, Guidelines for Responding to the Effects of Climate Change in Coastal and Ocean Engineering, prepared by the National Committee on Coastal and Ocean Engineering, Canberra. 
England, P. 2007, 'Climate change: what are local governments liable for?', Issues Paper 6, Urban Research Program, Griffith University, Queensland.

Furnass, B. 2007, 'Environmental and climate change refugees', Draft discussion paper for Doctors for the Environment, <http://www.manningclark.org.au/newsletter/nl30_furnass.html> viewed 16 March 2008.

Industry Commission 1991, 'Costs and Benefits of Reducing Greenhouse Gas Emissions', Volume I: Report, Volume II: Appendixes, Report No. 15, 15 November, Australian Government Publishing Service, Canberra.

Bolin, B., Houghton, J. T., Meira Filho, G., Watson, R. T., Zinyowera, M. C., Bruce, J., Lee, H., Callander, B., Moss, R., Haites, E., Acosta Moreno, R., Banuri, T., Dadi, Z., Gardner, B., Goldemberg, J., Hourcade, J-C, Jefferson, M., Melillo, J., Mintzer, I., Odingo, R., Parry, M., Perdomo, M., Quennet-Thielen, C., Vellinga, P., Sundararaman, N. 1995, IPCC Second Assessment Synthesis of Scientific-Technical Information relevant to interpreting Article 2 of the UN Framework Convention on Climate Change, http://www.ipcc.ch/pdf/climate-changes-1995/ 2nd-assessment-synthesis.pdf, viewed 27 February 2008.

Intergovernmental Panel on Climate Change (2007), Climate Change 2007: Impacts, Adaptation and Vulnerability. Contribution of Working Group II to the Fourth Assessment Report of the Intergovernmental Panel on Climate Change, Parry, M. L., Canziani, O. F., Palutikof, J. P., van der Linden, P. J. and Hansen C. E (eds), Cambridge University Press, UK.

Klein, R. J. T., Huq, S., Denton, F., Downing, T. E., Richels, R. G., Robinson, J. B., Toth F. L. 2007, 'Inter-relationships between adaptation and mitigation' in Intergovernmental Panel on Climate Change 2007: 745-77.

McMichael, A. J. 2004, 'Environmental and social influences on emerging infectious diseases: past, present and future', Philosophical Transactions of the Royal Society, London, B 359: 1049-58.

Nerkar, A., Paruchuri, S. and Khaire, M. 2007, 'Business method patents as real options: value and disclosure as drivers of litigation', in Reuer, J. J. and Tong T. W. (eds) 2007, Real Options Theory, volume 24 of Baum, J. A. C. (series editor), Advances in Strategic Management, Elsevier JAI, Oxford: 247-74

Nordvik, V. and Liso, K. R. 2004, 'A primer on the building economics of climate change', Construction Management and Economics 22, September: 765-75.

Orlove, B. 2005, 'Human adaptation to climate change: a review of three historical cases and some general perspectives', Environmental Science \& Policy 8: 589-600. 
Pielke, R., Prins, G., Rayner, S. and Sarewitz, D. 2007, 'Lifting the taboo on adaptation', Nature 445 (8 February): 597-8.

Pittock, B. (ed.) 2003, Climate Change: An Australian Guide to the Science and Potential Impacts, Commonwealth of Australia, Canberra.

Productivity Commission 1999, 'Implementation of Ecologically Sustainable Development by Commonwealth Departments and Agencies', Report No. 5, 25 May, AusInfo, Canberra.

Raynor, M. E. 2007, The Strategy Paradox: Why Committing to Success Leads to Failure (and What to do about it), Currency Doubleday, New York.

Schneider, S. H., Semenov, S., Patwardhan, A., Burton, I., Magadza, C. H. D., Oppenheimer, M., Pittock, A. B., Rahman, A., Smith, J. B., Suarez, A. and Yamin, F. 2007, 'Assessing key vulnerabilities and the risk from climate change' in Intergovernmental Panel on Climate Change (2007): 779-810.

Shashua-Bar, L. and Hoffman, M. E. 2004, 'Quantitative evaluation of passive cooling of the UCL microclimate in hot regions in summer, case study: urban streets and courtyards with trees', Building and Environment 39: 1087-99.

State of Victoria 2007, 'Climate Change and Infrastructure: Planning Ahead', information prepared by CSIRO, Department of Sustainability and Environment, Melbourne.

Taha, H. 1996, 'Modeling impacts of increased urban vegetation on ozone air quality in the South Coast Air Basin', Atmospheric Environment 30(20): 3423-30.

Tol, R. S. J. 2005, 'Adaptation and mitigation: trade-offs in substance and methods', Environmental Science \& Policy 8: 572-8.

Voice, M., Harvey, N. and Walsh, K. (eds) 2006, Vulnerability to Climate Change of Australia's Coastal Zone: Analysis of gaps in methods, data and system thresholds. Part II: Analysis for Costal Zone systems and components, report to the Australian Greenhouse Office, Canberra, June 2006.

Woodruff, R., McMichael, T. and Butler, C. 2006, 'Action on climate change: the health risks of procrastinating', Australian and New Zealand Journal of Public Health 30(6): 460-77. 